
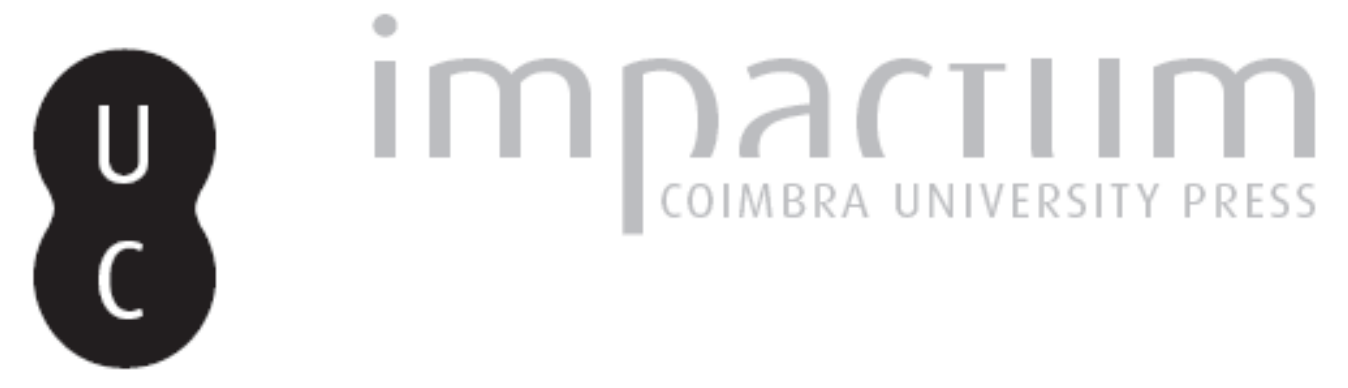

\title{
[Recensão a] KEN DOWDEN et NIALL LIVINGSTONE (2014), eds., A Companion to Greek Mythology
}

\author{
Autor(es): $\quad$ Rodrigues, Nuno Simões \\ Publicado por: Centro de História da Universidade de Lisboa \\ URL \\ persistente: \\ URI:http://hdl.handle.net/10316.2/38933 \\ DOI: \\ DOI:http://dx.doi.org/10.14195/0871-9527_24_10
}

Accessed : $\quad$ 26-Apr-2023 14:59:57

A navegação consulta e descarregamento dos títulos inseridos nas Bibliotecas Digitais UC Digitalis, UC Pombalina e UC Impactum, pressupõem a aceitação plena e sem reservas dos Termos e Condições de Uso destas Bibliotecas Digitais, disponíveis em https://digitalis.uc.pt/pt-pt/termos.

Conforme exposto nos referidos Termos e Condições de Uso, o descarregamento de títulos de acesso restrito requer uma licença válida de autorização devendo o utilizador aceder ao(s) documento(s) a partir de um endereço de IP da instituição detentora da supramencionada licença.

Ao utilizador é apenas permitido o descarregamento para uso pessoal, pelo que o emprego do(s) título(s) descarregado(s) para outro fim, designadamente comercial, carece de autorização do respetivo autor ou editor da obra.

Na medida em que todas as obras da UC Digitalis se encontram protegidas pelo Código do Direito de Autor e Direitos Conexos e demais legislação aplicável, toda a cópia, parcial ou total, deste documento, nos casos em que é legalmente admitida, deverá conter ou fazer-se acompanhar por este aviso.

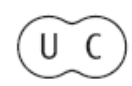




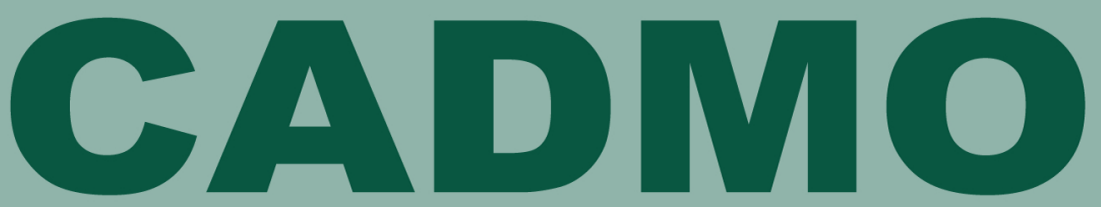

Revista de História Antiga

\section{Centro de História da Universidade de Lisboa}

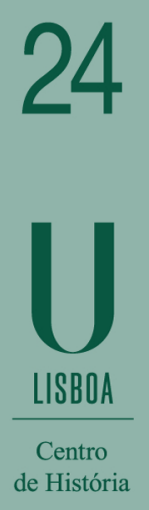

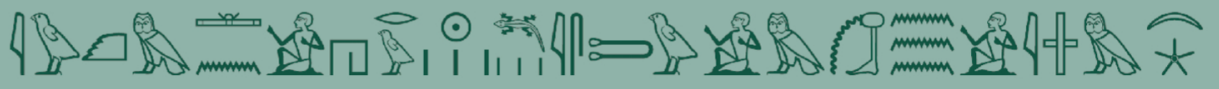

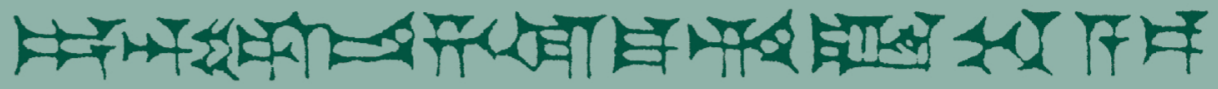
MHNIN AEI $\Delta$ E $\Theta E A ~ \Pi H \Lambda H I A \Delta E \Omega$ 
corpo e sexualidade (texto de M. Florence). Enfim, a sexualidade na história da Antiguidade Clássica tout court.

O volume revela-se assim uma perspectiva abrangente, se não mesmo completa, da problemática, sendo sempre preocupação dos vários autores a apresentação de leituras de síntese essencialmente baseadas nas fontes antigas. Integrado na já tradicional linha dos «Companions» da Blackwell, este livro vem preencher mais uma lacuna e ao mesmo tempo confirmar que a História da Sexualidade ou dos comportamentos sexuais e suas percepções não foi um epifenómeno que se terá esgotado com os trabalhos de M. Foucault. Antes pelo contrário.

Cada artigo é acompanhado da respectiva bibliografia de referência, a qual se restringe, como necessário, às obras fundamentais no domínio de cada tema estudado. No entanto, se procedermos a uma listagem completa dos textos referidos em cada bibliografia individual, obteremos uma perspectiva assinalável do quanto se tem escrito neste domínio. Um índice final de passos citados enriquece substancialmente o volume. Nunca é demais recordar que este é instrumento precioso para os investigadores. Por outro lado, sentimos falta de um índice remissivo/topo-antroponímico.

Nuno Simões Rodrigues

KEN DOWDEN et NIALL LIVINGSTONE (2014), eds., A Companion to Greek Mythology, Oxford, Blackwell Publishing Ltd., 643 pp. ISBN 978-1-4051-1178-2 (£32.50).

Esta é a edição paperback do "Companion» de Mitologia Grega da Blackwell, originalmente publicado em hardback, em 2011. O livro é composto por seis partes, as quais são introduzidas por um denso texto dos editores, K. Dowden e N. Livingston, que tem como objectivo sobretudo apresentar as várias perspectivas epistemológicas de que o mito se tem sustentado ao longo dos séculos. Neste sentido, a introdução dos AA. não só cumpre o seu objectivo como é da maior utilidade enquanto «estado da arte» no que diz respeito a esta problemática.

A Parte I, «Establishing the Canon» (pp. 25-106), aborda essencialmente a problemática das fontes mitológicas, regressando aos textos fundacionais da cultura grega, i.e. os Poemas Homéricos (com texto 
de F. Létoublon) e Hesíodo (texto de K. Dowden), aos quais se junta uma reflexão de R. G. Edmonds III sobre a mitologia órfica. Teria sido interessante encontrar nesta parte textos introdutórios a Higino, Apolodoro, Eratóstenes, Antonino Liberal e, claro, Ovídio. Tão-somente porque se trata igualmente de mitógrafos clássicos, apesar de quase todos radicados nas fontes homéricas e hesiódicas, e como tal bases de pesquisa nestas matérias.

A Parte II, «Myth Performed, Myth Believed» (pp. 107-207), aborda problemáticas como o recurso ao corpus mitológico enquanto matéria poética (textos de I. Rutherford, J. Alaux), mas também filosófica (textos de N. Livingston e P. Murray), histórica (texto de A. Griffiths) e artística (texto de S. Woodford). Em suma, trata-se da expressão mitológica nas plataformas essenciais da cultura grega.

A Parte III, «New Traditions» (pp. 209-337), assenta sobretudo em questões de recepção da mitologia grega, contudo, na própria Antiguidade. O período helenístico (textos de F. Graf, A. Mori e K. Dowden), o mundo romano (textos de M. Fox e de Z. Newbye) e o cristianismo (texto de F. Graf) são os temas que funcionam como perspectivas a partir das quais se reconsidera o mito grego nesta parte.

A Parte IV, «Older Traditions» (pp. 339-410), traz à colação a pertinente questão das influências orientais, mas também a do indo-europeísmo, na mitologia grega. Aqui encontramos textos de N. J. Allen, A. Livingstone, B. Haskamp, N. Marinatos e N. Wyatt.

A Parte V, «Interpretation» (pp. 411-524), é a mais heterogénea do volume, contendo reflexões sobre questões fundamentais da mitologia grega, como e.g. a problemática de Tróia (texto de D. Hertel), questões de género (texto de $\mathrm{S}$. Lewis) ou de etnia/cultura (texto de I. Rutherford). Mas aqui encontramos também uma interessantíssima exposição sobre as teorias da psicanálise e sua relação com a mitologia grega (texto de R. H. Armstrong).

A VI e última parte, «Conspectus» (pp. 527-547), funciona como conclusão do volume, na qual lemos sobre o estudo da Mitologia Grega ao longo dos séculos, num texto de J. N. Bremmer.

Há que referir que este é um dos volumes mais completos da colecção dos Companions Blackwell. Nele encontramos úteis índices de passos citados, mas também de nomes e assuntos. Este livro consagra-se assim como um instrumento essencial para todos os estudiosos da mitologia clássica. 